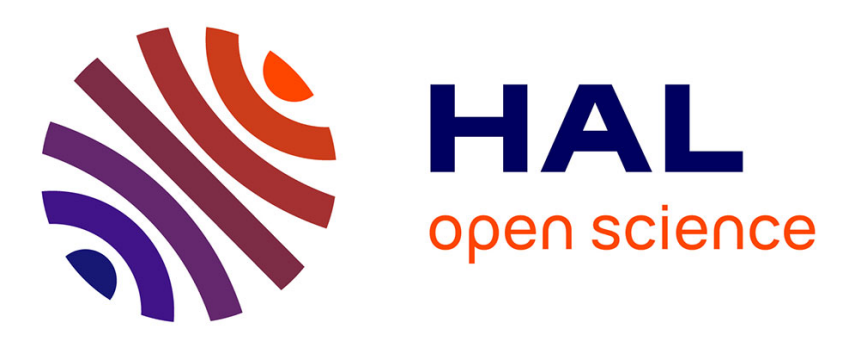

\title{
Seasonal fate and gas/particle partitioning of semi-volatile organic compounds in indoor and outdoor air
}

Elodie Moreau-Guigon, Fabrice Alliot, Johnny Gasperi, Martine Blanchard, Marie-Jeanne Teil, Corinne Mandin, Marc Chevreuil

\section{To cite this version:}

Elodie Moreau-Guigon, Fabrice Alliot, Johnny Gasperi, Martine Blanchard, Marie-Jeanne Teil, et al.. Seasonal fate and gas/particle partitioning of semi-volatile organic compounds in indoor and outdoor air. Atmospheric Environment, 2016, 147, pp.423-433. 10.1016/j.atmosenv.2016.10.006 . hal-01379888

\section{HAL Id: hal-01379888 \\ https://hal-enpc.archives-ouvertes.fr/hal-01379888}

Submitted on 10 Nov 2016

HAL is a multi-disciplinary open access archive for the deposit and dissemination of scientific research documents, whether they are published or not. The documents may come from teaching and research institutions in France or abroad, or from public or private research centers.
L'archive ouverte pluridisciplinaire HAL, est destinée au dépôt et à la diffusion de documents scientifiques de niveau recherche, publiés ou non, émanant des établissements d'enseignement et de recherche français ou étrangers, des laboratoires publics ou privés. 


\section{ACCEPTED MANUSCRIPT}

Seasonal fate and gas/particle partitioning of semi-volatile organic compounds

4 Elodie Moreau-Guigon ${ }^{1}$, Fabrice Alliot ${ }^{1}$, Johnny Gaspéri ${ }^{2}$, Martine Blanchard ${ }^{1}$, Marie-Jeanne Teil ${ }^{1}$, Corinne 5 Mandin $^{3}$, Marc Chevreuil ${ }^{1}$

6

7 '1: EPHE, PSL Research University, UPMC Univ Paris 06 - CNRS, UMR 7619 METIS , F-75005, Paris, France.

$8 \quad$ 2: Université Paris-Est, LEESU, UMR MA 102 - AgroParisTech, F-94000 Créteil, France.

9 3 : Université Paris-Est, Centre Scientifique et Technique du Bâtiment (CSTB), F-77447 Marne-La-Vallée, 10 France.

11

$12 *$ Corresponding author: elodie.moreau-guigon@upmc.fr 
ACCEPTED MANUSCRIPT

Abstract: Fifty-eight semi-volatile organic compounds (SVOCs) were investigated simultaneously in three indoor (apartment, nursery and office building) and one outdoor environment in the centre of Paris (France). All of these compounds except tetrabromobisphenol A were quantified in the gaseous and particulate phases in all three environments, and at a frequency of $100 \%$ for the predominant compounds of each SVOC class. Phthalic acid esters (PAEs) were the most abundant group (di-iso-butyl phthalate: $29-661 \mathrm{ng} \cdot \mathrm{m}^{-3}$, diethyl phthalate: $15-542 \mathrm{ng} \cdot \mathrm{m}^{-3}$ ), followed by $4-$ nonylphenol (1.4-81 ng. $\mathrm{m}^{-3}$ ), parabens (methylparaben: 0.03-2.5 $\mathrm{ng} \cdot \mathrm{m}^{-3}$ ), hexachlorobenzene (HCB) (0.002-0.26 ng.m ${ }^{-3}$ ) and pentachlorobenzene (PeCB) (0.001-0.23 ng.m ${ }^{-3}$ ). Polycyclic aromatic hydrocarbons (as $\sum 8 \mathrm{PAHs}$ ) ranged from 0.17 to $5.40 \mathrm{ng} \cdot \mathrm{m}^{-3}$, polychlorinated biphenyls (as ¿7PCBi) from 0.06 to $4.70 \mathrm{ng} . \mathrm{m}^{3}$ and polybromodiphenyl ethers (as ¿8PBDEs) from 0.002 to 0.40 $\mathrm{ng} \cdot \mathrm{m}^{-3}$. For most pollutants, significantly higher concentrations were observed in the nursery compared to the apartment and office. Overall, the indoor air concentrations were up to ten times higher than outdoor air concentrations. Seasonal variations were observed for PAEs, PCBs and PAHs. SVOCs were predominantly identified in the gaseous phase (>90\%), except for some highmolecular-weight PAEs, PAHs and PCBs.

Key-Words: indoor air, outdoor air, semi-volatile organic compounds, gaseous phase, particulate phase, gas/particle partitioning.

\section{Highlights}

- Quantification of 58 semi-volatile organic compounds in indoor and outdoor air.

- Phthalates at highest concentrations in all environments whatever the season.

- Higher indoor air concentrations in a nursery than in an apartment or office.

- First determination of gas/particle partitioning for parabens.

- Most pollutants in gaseous phase whatever the environment. 


\section{Introduction}

In recent decades, a wide variety of semi-volatile organic compounds (SVOCs) have been detected in the environment and health damage associated with exposure to SVOCs has been reported. Human exposure to these priority substances during fœtal development or early life has been associated with adverse birth outcomes and neurotoxic, immunotoxic and obesogenic effects in children (Casas et al., 2013).

However, few studies have simultaneously quantified a large number of these compounds in indoor air (Blanchard et al., 2014; Rudel and Perovich, 2009; Mandin et al., 2016). Some of the studied compounds, such as diethylhexyl phthalate (DEHP), bisphenol A (BPA), 4-nonylphenol (4NP) and polybromodiphenyl ethers (PBDEs), have been registered on the European priority list of the registration evaluation and authorization of chemicals system (Reach, 2015).

Given their widespread use in building materials and consumer products for many years, SVOCs are ubiquitous in indoor environments (Blanchard et al., 2014; Laborie et al., 2016). Indeed, synthetic flooring, plastic items, detergents and electronic appliances such as televisions and computers have introduced new chemicals into indoor environments because of their particular properties (flame retardants, biocides, refrigerants, surfactants, etc.) (Weschler, 2009). Moreover, in densely urbanized areas, it appeared that indoor environments were a major source of pollutants for outdoor ambient air (Rudel and Perovich, 2009).

SVOCs may be found adsorbed upon airborne particles, as well as in the gaseous phase. Most literature data pertain to airborne particles, the gas phase, or the total air concentration for several families of pollutants, but few studies have considered the gaseous and the particulate phases simultaneously and individually (Blanchard et al., 2014; Fromme et al., 2009; Rudel et al., 
2010; Weschler et al., 2008). Few data are available for some compounds such as PBDEs, particularly in the gas phase in indoor and outdoor environments (Blanchard et al., 2014).

Moreover, validation of models for the indoor environmental fate and human exposure such as those described by Zhang et al. (2014) and prediction of gas/particle distribution from empirical equations (Wei et al., 2016) require a great number of experimental data.

Thus, the overall objective of this study was to investigate SVOC occurrence in both the gaseous and particulate phases of ambient air from different indoor environments. A wide variety of SVOCs with distinct physico-chemical properties were targeted on the basis of their probable occurrence in indoor air, their associated health concerns (Bonvallot et al., 2010) and the technical feasibility of measurement simultaneously (Alliot et al., 2014). These compounds comprised seven phthalic acid esters (PAEs), BPA, two alkylphenols (APs), four parabens, eight PBDEs, tetrabromobisphenol-A (TBBPA), 18 PCBs, hexachlorobenzene (HCB), pentachlorobenzene (PeCB) and 15 PAHs.

PAEs are ubiquitous environmental chemicals because they have been used as plasticizers for more than 40 years and their applications are diverse, ranging from cosmetics or flooring to pharmaceutical products and medical devices (Fromme et al., 2009). DEHP, with a high-production volume of around 200000 tons in the European Union, is mainly used in polyvinyl chloride (Gaudin et al., 2011). Dimethyl (DMP) and diethyl (DEP) phthalates are commonly found in cosmetics as carriers or solvents for synthetic musks (Sanchez-Prado et al., 2011). European legislation has prohibited the use of DEHP for manufacturing single-use food packaging films. However, DnBP and BBP are authorized in single-use packaging for fat-free food storage. In addition, in the cosmetic industry, DEHP, BBP, n-pentyl, di-n-pentyl, iso-pentyl and di iso-pentyl phthalate have been forbidden (Directive 2004/93/EC, 2004; Directive 2005/80/EC, 2005). DEHP, DBP and BBP are prohibited in the manufacture of toys and childcare articles and the prohibition of DnOP, di-iso nonyl phthalate (DiNP) and di-iso-decyl phthalate (DiDP) is limited to toys and childcare articles 
(Directive 2005/84/EC, 2005). BPA is used in polycarbonate plastics in many consumer products and in the epoxy resins lining food and beverage containers (WHO, 2011). APs, including nonylphenol and octylphenol, are used as nonionic surfactants in detergents and cleaning products and also in some pesticide formulations and industrial products (Ying et al., 2002). Parabens are used as a preservative in personal care products (Błędzka et al., 2014). Among the three major commercial PBDE mixtures, penta- and octa-BDEs have been banned in all applications for the European Union market since 2004 (Directive2003/11/EC, 2003). Deca-BDEs registered under the $\mathrm{REACH}$ regulation in 2010 have been restricted to applications such as automotive equipment, textiles and construction and have been prohibited for electric and electronic equipment (BSEF, 2012). PCBs, no longer produced or used, may still be found in indoor air (Hazrati and Harrad, 2006; Heinzow et al., 2007). Finally, PAHs are combustion or industrial byproducts. However, in some cases, indoor air contamination by PAHs might originate from glues containing coal tar (Heudorf and Angerer, 2001).

The main objectives of this study were to i) prioritize the concentrations of the 58 SVOCs in indoor air for three different buildings in the centre of Paris and to compare them with outdoor air levels, ii) evaluate the seasonal influence on indoor concentrations, iii) investigate SVOC partitioning between the gaseous and particulate phases and iv) explore the relationships between the different SVOCs.

\section{Material and methods}

\subsection{Sampling sites}

Two sampling campaigns were carried out, each over a 6-week period: the first was performed during the non-heating period (from September $21^{\text {st }}$ to November $3^{\text {rd }}, 2011$ ), and the second was performed during the heating period (from January $23^{\text {rd }}$ to March $5^{\text {th }}, 2012$ ). Each sampling campaign included three successive 2-week periods. The outdoor air samples, concomitant with the indoor samples, came out of a larger study on outdoor air pollution in Paris, 
112

from 2009 to 2012 published in Teil et al. (2016). Three different indoor environments were considered: a non-smoking apartment where two adults were living, a nursery $(20$ toddlers + six adults) and an office building (two persons). Their occupants voluntarily participated in this study. They exhibited no special equipment that might have impeded the results as there was no kitchen or cafeteria in the office building. The three buildings were equipped with mechanical ventilation systems.

All the sampling sites were located in densely urbanized areas. The nursery and the office were located at a single site in the centre of Paris ( $5^{\text {th }}$ arrondissement), in a group of buildings built in 1965 and refurbished in 2003. The apartment was situated in a building constructed in 1993 located in the East of Paris (Les Lilas). The nursery and the office were located approximately $4 \mathrm{~km}$ from the apartment and $1.7 \mathrm{~km}$ from the outdoor monitoring station (Airparif monitoring station, Paris $13^{\text {th }}$ arrondissement).

\subsection{Sampling procedure}

Both the gaseous and particulate phases of the air were collected at the outdoor and three indoor sites. The sampler consisted of a filter holder (Ecomesure, Janvry, France), two serial cartridges for the XAD-2 resin, a sampling pump (Busch, model SV1005GP, Maulburg, Germany) and a ball flow metre (Hivolin, Germany). The sampling technique was derived from the method described by Granier and Chevreuil (1997). The design of the sampling device and its implementation followed the established recommendations for sampling a gas phase more or less charged with particles (AFNOR, 2003). The efficiency of the adsorption was monitored by adding a second resin cartridge which also allows one to increase the height of the adsorbent and the contact period. Using two cartridges with a small section instead of one large cartridge prevents the emergence of a preferential circulation pathway of air through the resin. Thus, according to the above-mentioned standard, about $90 \%$ of the gaseous phase was quantified in the first cartridge (Alliot et al., 2014). 
The sampling system is shown in SI-Appendix 1. The air flow rate was $0.6 \mathrm{~m}^{3} \cdot \mathrm{h}^{-1}$ (medium sampling volume), and the volume collected ranged from 129 to $175 \mathrm{~m}^{3}$. The particulate phase was collected in total suspended particulate mode (TSP) onto a 47-mm quartz fibre filter (Q-MA, supplied by Whatman), previously heated to $400^{\circ} \mathrm{C}$ for $4 \mathrm{~h}$. These filters display an air retention capacity greater than or equal to $\geq 99.95 \%$ for particles $\geq 0.3 \mu \mathrm{m}$. The gaseous phase was collected onto XAD-2 resin (20-60 mesh, Sigma-Aldrich, Saint-Quentin Fallavier, France) cleaned by Soxhlet extraction with methanol, acetone and hexane/ether $(90 / 10, v / v)$ and stored at $4^{\circ} \mathrm{C}$ before use. Thirteen grams of XAD-2 were used in two brass cartridges (13 $\mathrm{mm}$ in diameter; $10 \mathrm{~cm}$ long).

The indoor air sampling was conducted according to the recommendations of the Swiss Federal Office of Public Health (Waeber et al., 2012). The samples from the apartment were collected in a single room where people spent most of time, i.e., the living room. To minimize artefacts due to air-flow variations close to the walls, the sampling locations in the three indoor locations were set a minimum of $1 \mathrm{~m}$ from the wall and $1.50 \mathrm{~m}$ high to avoid the suspension of settled particles. The sampling flow of $0.6 \mathrm{~m}^{3} \cdot \mathrm{h}^{-1}$ corresponded to $2 \%$ per hour of the smallest room volume $\left(30 \mathrm{~m}^{3}\right)$ and was below the $10 \%$ value recommended by Waeber et al. (2012) to avoid depletion of compounds in the room air and possible artefact consisting of particle phase overestimation, and to minimize any change under steady state conditions. The sampling conditions are detailed in SI-Appendix 2. The sampling air velocity through the system varied from 80 to $150 \mathrm{~cm} \cdot \mathrm{s}^{-1}$, i.e. lower than the maximum flow of $170 \mathrm{~cm} \cdot \mathrm{s}^{-1}$ recommended by the IEPA method (IEPA/APC, 1985), to optimize the gaseous phase retention on the XAD-2 resin. The indoor temperatures were continuously monitored during the sampling periods with Voltcraft devices (DL-141TH) (Conrad Electronic, Poissy, France). The temperature remained stable in the three indoor environments. Total suspended particulates (TSP) were determined by gravimetry and expressed as $\mu \mathrm{g} \cdot \mathrm{m}^{-3}$ (SI-Appendix 2). Questionnaires were distributed to the occupants to i) provide basic information for interpretation of the results (smoking, frying, use of sprays, cleaning 
habits, window opening) and ii) record any particular event that might occur during the sampling period (SI-Appendix 3).

\subsection{Analytical procedure}

Fifty-eight compounds from different chemical families were analyzed in the gaseous and particulate phases. The list of molecules is presented in SI-Appendix 4. The analytical procedure is described in Alliot et al. (2014). Internal standards were added to the gaseous and particulate phase samples before extraction (SI-Appendix 5). The XAD-2 resins were extracted in a polypropylene cartridge by percolation/depression with $100 \mathrm{~mL}$ of dichloromethane on a Visiprep system (Supelco). The filters were extracted with $10 \mathrm{~mL}$ of hexane/acetone (1:1) by ultrasonic treatment for $20 \mathrm{~min}$. Then each extract was divided into two aliquots. The first aliquot (80\%) was retained for the quantification of PCBs, PAHs, PBDEs, PAEs and parabens, and the second aliquot (20\%) was retained for the quantification of APs. All experimental procedures (sampling + clean-up + fractionation) and validations for sampling, extraction and analytical methods have been published previously (Alliot et al., 2014).

The first aliquot was fractionated upon a Florisil cartridge in three fractions. The F1 fraction was purified on a multi-layer column (neutral alumina activated at $150^{\circ} \mathrm{C} /$ silica activated at $150^{\circ} \mathrm{C}$ ), and PAHs were analyzed; then the extracts were purified by acidification before analysis for PCBs and PBDEs. The two other fractions were not purified. F1, F2 and F3 were analyzed by gas chromatography-mass spectrometry (GC-MS), gas chromatography-tandem mass spectrometry (GC-MS/MS) or high-performance liquid chromatography tandem mass spectrometry (HPLCMS/MS) depending on the compounds sought. The second aliquot was analyzed by UPLC-MS/MS using the method of Cladiere et al. (2013). The limits of detection (LODs) and the limits of quantification (LOQs) are provided in SI-Appendix 5.

\subsection{QA/QC}


The compounds were quantified by internal calibration. Syringe standards were added to the vials prior to analyses to estimate the internal standard recoveries $\left({ }^{13} C_{12}\right.$ PCB194, CB209, BB209 and benzyl benzoate). Recoveries were previously assessed for all the target compounds. After extraction and purification, recoveries for the gaseous phase ranged from $30 \%$ (TBBPA) to $136 \%$ (CB-169), depending on the compound. The retention capacity of the XAD-2 cartridges was also tested (Alliot et al., 2014). Almost all compounds were retained by the first cartridge (at least $90 \%$ of the amount trapped). The resins from the two cartridges were mixed and extracted as a single sample to avoid compound losses.

The concentrations were corrected by concomitant blank concentrations for all compounds. With the exception of PAEs, all blanks were in accordance with analysis quality (SI, Appendix 5). Peaks were integrated only when the signal-to-noise ratio was $\geq 3$, and peaks were quantified when the signal-to-noise ratio was $\geq 9$, peak to peak.

\subsection{Data analysis}

\section{Concentrations}

Concentrations were expressed as medians, minima (MIN), maxima (MAX) and means \pm standard deviation (SD). The concentrations in both the gaseous and particulate phases were expressed as ng. $\mathrm{m}^{-3}$. Total concentrations in air, expressed as $\mathrm{ng} \cdot \mathrm{m}^{-3}$, were the sums of the gaseous and particulate phases. The results were expressed as the sum of all compounds in each family ( $($ compounds) and as individual compounds representative of each family (SI-Appendix 3).

The PAEs were expressed as I7PAEs (dimethyl phthalate (DMP), diethyl phthalate (DEP), di-nbutyl phthalate (DnBP), di-iso-butyl phthalate (DiBP), butylbenzyl phthalate (BBzP), diethylhexyl phthalate (DEHP) and di-n-octyl phthalate (DnOP)).

The PCBs were expressed as $\angle$ PCBi (seven PCB indicators: CB28, 52, 101, 118, 138, 153 and 180), SPCB-DL (CB77, 81, 126, 169 for non-ortho PCBs dioxin-like and CB105, 114, 118, 123, 156, 157, 167, 189 for mono-ortho PCBs dioxin-like) and $219 P C B s$. 
211 The target PAHs were (i) fluorene (FLU) and phenanthrene (PHE), which are predominantly low212 molecular-weight compounds; (ii) chrysene (CHR) whose molecular weight $=228 \mathrm{~mol} \mathrm{~g}^{-1}$; (iii) 213 benz[a]anthracene $(\mathrm{BaA})$ and benzo[a]pyrene (BaP), which are carcinogens; and (iv) 214 benzo[ghi]perylene (BghiP), which has the highest molecular weight of the compounds studied. 215 CHR appeared to be the dividing line for the PAHs with a larger or smaller distribution in the 
accordance with the production, USE, regulation and physico-c

accordance with the production, use, regulation and physico-chemical properties of the

compounds. The world production of PAEs and APs are estimated at 4.3 million tons ( 1 million for

Europe) and 500000 tons per year, respectively (Peijnenburg and Struijs, 2006; Ying et al., 2002).

The annual global atmospheric emission of 16 PAHs in 2013 was estimated at 504000 tons by Chen et al. (2013).

For PAEs, parabens, APs and FLU, significantly higher concentrations were observed in the nursery than in the apartment and the office $(p<0.05)$. These concentrations were 1.5 to two times higher in the nursery than in the apartment and the office for PAEs, two to five times higher for parabens and two to six times higher for APs. The highest concentrations were observed in the nursery for all compounds associated with children's products such as toys or widely used care products. Moreover, the apartment showed significantly lower PCB concentrations than the office and the nursery $(p<0.05)$ (Table 2$)$.

\section{Plasticizers}

PAEs were quantified at a frequency of $100 \%$ in the three indoor environments, except BBzP and DnOP, the levels of which were close to the LOQs (Table 1, SI-Appendix 5, SI-Appendix 6). As previously reported in California (Rudel et al., 2010; Rudel and Perovich, 2009), PAEs were ubiquitous in indoor air. The concentrations as E7PAEs ranged from 71 to $1362 \mathrm{ng} \cdot \mathrm{m}^{-3}$. Concentrations in the same range (from 143 to $2600 \mathrm{ng} \cdot \mathrm{m}^{-3}$ as L9PAEs) were found in different indoor environments including homes, offices and schools in the USA (Tran and Kannan, 2015).

DiBP, DnBP and DEP prevailed in the three indoor environments. This should be expected because of their presence in many consumer products (Viñas et al., 2015) and their higher vapor pressures $\left(3.610^{-3} \mathrm{~Pa}\right.$ for DiBP and DnBP and 0.130 Pa for DEP at $25^{\circ} \mathrm{C}$ ) compared to other PAEs (Staples et al., 1997). However, two different compound sequences - DiBP (29-661 ng.m ${ }^{-3}$ ), followed by DEP (15-418 ng.m $\mathrm{m}^{-3}$ ) and DnBP (11-136 ng. $\left.\mathrm{m}^{-3}\right)$ - prevailed in the office and the apartment, while DEP $\left(146-542 \mathrm{ng} \cdot \mathrm{m}^{-3}\right)$ was predominant in the nursery $(\mathrm{p}<0.05$, Table 2$)$. This 
can be due to differences in the number and type of sources such as daily cleaning inside the nursery (SI-Appendix 3) and repeated use of body care products for children. Indeed, determination of PAEs in cleaning and personal care products in Spain showed a preponderance of DEP, particularly in body lotion and floor cleaner (Viñas et al., 2015). In addition, the higher indoor temperature (SI-Appendix 2), which was $21.7^{\circ} \mathrm{C}$ for the non-heating season and $23.6{ }^{\circ} \mathrm{C}$ for the heating season in the nursery, compared with $19.3^{\circ} \mathrm{C}$ and $20.3^{\circ} \mathrm{C}$ in the apartment, and $20.3^{\circ} \mathrm{C}$ and $21.5^{\circ} \mathrm{C}$ in the office, could contribute to higher air concentrations inside the nursery.

Higher orders of magnitude of DEP (130-4300 ng.m ${ }^{-3}$ ) and DnBP (52-1100 ng.m $\left.\mathrm{m}^{-3}\right)$ were found in dwellings at Cape Cod (USA), and the following sequence DEP > DnBP > DiBP was found in air from apartments in California (USA) (Rudel et al., 2010, 2003). In the Stockholm area (Sweden), the same predominant compounds were reported in indoor air from three different environments i.e., homes, day care centres and workplaces. Their concentrations were higher than ours, except for DMP. Offices appeared to be less contaminated by PAEs, with a ¿6PAEs of $1500 \mathrm{ng} \cdot \mathrm{m}^{-3}$, followed by nurseries with $1900 \mathrm{ng} \cdot \mathrm{m}^{-3}$ and then homes with $2700 \mathrm{ng} \cdot \mathrm{m}^{-3}$ (Bergh et al., 2011). The prevalence of these compounds might be related to their current use, given that they are present in cosmetics and personal care products (Guo et al., 2013).

Overall, DEHP accounted for only $3-9 \%$ of the total PAE concentrations. A similar distribution of compounds, with DiBP predominating and lower concentrations of DEP, was observed in French dwellings (Blanchard et al., 2014). Furthermore, the materials used for furnishing might influence these concentrations. DEHP can be emitted to the air from PVC flooring (Xu et al., 2009). Indeed, in 16 types of vinyl flooring tested in the USA, DEHP was the most abundant ( 7 to $23 \%$ ) followed by DiNP (20\%) then DnBP (9\%) (Liang and Xu, 2014a). The apartment, devoid of PVC flooring in contrast to the office and the nursery, displayed the lowest DEHP concentrations. Moreover, the lower mean temperature in the apartment could influence DEHP volatilization compared with the other environments. 
Whatever the indoor environment and the season BPA showed very low concentrations $(<1$

ng. $\mathrm{m}^{-3}$ ). This compound is characterized by a vapour pressure of $5.310^{-5} \mathrm{~Pa}$ at $25^{\circ} \mathrm{C}$ (Staples et al.,

1998) and is chemically bound to a polymer matrix (Brunelle, 2002), which limits passive emission

from materials. Among the three sites, the mean concentration trend was nursery $>$ apartment $>$

office, possibly related to the abundance of equipment and plastic materials in the nursery relative

to other environments. Data in the literature concerning indoor BPA were scarce. However, our

concentrations were on the same order of magnitude as concentrations measured in apartments

(Rudel et al., 2010), houses and day care centres (Wilson et al., 2007) in the USA and dwellings and offices in Japan (Inoue et al., 2006).

\section{Surfactants}

APs $(O P+4-N P)$ were the second group by order of prevalence, showing a range of concentrations from 1.65 to $90.9 \mathrm{ng} \cdot \mathrm{m}^{-3}$. 4-NP is a relatively volatile compound (vapour pressure: $0.1 \mathrm{~Pa}$ at $25^{\circ} \mathrm{C}$, (TOXNET, 2014)) and was the most common, with a contribution from 90 to $96 \%$ of the total APs. This trend was similar in the three indoor environments. The results indicate higher concentrations in the nursery compared to offices and the dwelling $(p<0.05$, Table 2$)$. Building materials (concrete, cement, paint), which were similar in the nursery and the office, and the daily use of detergents for surface cleaning in the nursery could be implicated in the indoor emissions (SI-Appendix 4). Very few studies concerning APs in indoor air are available. In the USA, 4-NP was detected in 95-100\% of houses (Rudel et al., 2010). Our concentrations were on the same order of magnitude as those measured in homes in the USA and Japan (Rudel et al., 2010; Saito et al., 2004).

\section{Preservatives}

Parabens were the group of SVOCs that showed the greatest discrepancies between buildings, with concentration ratios from 1 to 5 . Due to their primary use as antioxidants and preservatives, the concentrations were higher in collective locations $(p<0.05)$ - the nursery $\left(3.70 \pm 0.89\right.$ ng. $\left.\mathrm{m}^{-3}\right)$ 

and office $\left(1.70 \pm 0.73 \mathrm{ng} \cdot \mathrm{m}^{-3}\right)-$ than in the apartment $\left(0.74 \pm 0.62 \mathrm{ng} \cdot \mathrm{m}^{-3}\right)$ (Table 2). These compounds are relatively volatile, and among the four compounds investigated, the two dominant compounds were MeP $\left(0.8 \mathrm{~Pa}\right.$ at $\left.25^{\circ} \mathrm{C}\right)$ and $\operatorname{PrP}\left(4.73 \mathrm{~Pa}\right.$ at $\left.25^{\circ} \mathrm{C}\right)$ (Ramirez et al., 2010). In the USA, a similar compound distribution was observed, with MeP being the major compound detected in indoor air in $67 \%$ of homes with a median concentration of 2.9 ng.m ${ }^{-3}$ (Rudel et al., 2003).

\section{PCBs and organochlorine compounds}

Despite the successive restrictions for the use of PCBs in 1976 and their prohibition in 1986 in France, these organochlorine compounds remain omnipresent in all environmental compartments. Indeed, new "non-aroclor" PCBs were detected as by-product of diarylide yellow (Rodenburg et al., 2010) and other types of pigment production (Anezaki et al., 2015). The concentrations found herein (Figure 1) were on the same order of magnitude as those observed in homes and offices in the UK and Canada between 2003 and 2006 (Hazrati and Harrad, 2006; Zhang et al., 2011). For the three living spaces, CB52, which is relatively volatile with a vapour pressure at $25^{\circ} \mathrm{C}$ of $0.01 \mathrm{~Pa}$ (Burkhard et al., 1985), was the major compound, followed by CB28 and CB101 in equal proportions (Table 1, SI-Appendix 6). This pattern is consistent with the literature, especially in places situated away from combustion process emission sources (Granier and Chevreuil, 1991; Hazrati and Harrad, 2006; Zhang et al., 2011). Our study showed similar PCB patterns among the three indoor environments. It should be noted that a similar congener pattern was reported in the air of apartments from urban areas in Italy (Menichini et al., 2007).

The nursery and office showed mean concentrations of $\Sigma \mathrm{PCBi}$ higher than that in the apartment (1.75 \pm 1.82 and $1.48 \pm 0.63 \mathrm{ng} \cdot \mathrm{m}^{-3}$, respectively, versus $\left.0.55 \pm 0.36 \mathrm{ng} \cdot \mathrm{m}^{-3} ; \mathrm{p}<0.05\right)$ (Table 2). This difference could be explained by the fact that the buildings and the site had been contaminated by PCBs for a long time before being refurbished. Additionally, slightly lower PCB concentrations were found in the air of homes than in offices in Toronto (Canada) by Zhang et al. 
(2011). PCB levels from 2 to 8.3 ng. $\mathrm{m}^{-3}$ were measured in the indoor air of apartments in urban areas in Italy (Menichini et al., 2007). Similarly, a median concentration of $4 \mathrm{ng} \cdot \mathrm{m}^{-3}$ was observed in 181 public buildings in Germany. These buildings were mainly schools built between 1960 and 1975 , which corresponds to the same time frame of the construction of our office and nursery (Heinzow et al., 2007).

The average concentrations of HCB (office: $0.111 \pm 0.035 \mathrm{ng} \cdot \mathrm{m}^{-3}$; apartment: $0.120 \pm 0.092$ ng. $\mathrm{m}^{-3}$; nursery: $0.082 \pm 0.084$ ng. $\mathrm{m}^{-3}$ ) and PeCB (office: $0.132 \pm 0.048$ ng. $\mathrm{m}^{-3}$; apartment: $0.136 \pm$ $0.082 \mathrm{ng} \cdot \mathrm{m}^{-3}$; nursery: $0.051 \pm 0.054 \mathrm{ng} \cdot \mathrm{m}^{-3}$ ) remained low and varied slightly between buildings and seasons, with the lowest values being observed in the nursery for the non-heating period. The agricultural use of HCB as a fungicide has been banned in France since 1972. Recent sources of this persistent organic pollutant and its degradation by-product, $\mathrm{PeCB}$, are mainly related to transport (50\%) and accidental synthesis by industrial processes (29\%) (CITEPA, 2014).

\section{Flame retardants}

PBDEs were always detected, regardless of the season and indoor environment, and BDE209 and BDE47 were predominant. The highest $\angle 8 P B D E s$ concentrations were observed in the office $\left(0.132 \pm 0.130 \mathrm{ng} \cdot \mathrm{m}^{-3}\right)$, while similar concentrations were found in the apartment $(0.055 \pm 0.060$ $\left.\mathrm{ng} \cdot \mathrm{m}^{-3}\right)$ and the nursery $\left(0.044 \pm 0.052 \mathrm{ng} \cdot \mathrm{m}^{-3}\right)$. PBDE concentrations were close to those found in buildings in Europe, on the order of magnitude of several hundred $\mathrm{pg} \mathrm{m}^{-3}$, with BDE209 followed by BDE47 present at higher concentrations in houses and apartments than in nurseries (Fromme et al., 2009; Thuresson et al., 2012). BDE47 was the most volatile BDE detected (vapour pressure $2.1510^{-4} \mathrm{~Pa}$ (Wania and Dugani, 2003)) and the most abundant in the office. TetraBDEs and pentaBDEs have not been produced in the EU since 1997, but they were mainly used in applications with a long lifetime, such as in automotive and upholstery applications, that are still in use (European Commission, 2014). Moreover, formation of nona- to tri-BDE congeners by solar photodecomposition of BDE209 has been reported (Bezares-Cruz et al., 2004). Our results are 


\section{ACCEPTED MANUSCRIPT}

consistent with those reported in Sweden by Thuresson et al. (2012) and de Wit et al. (2012), who found maximum values in offices $\left(4.0 \mathrm{ng} \cdot \mathrm{m}^{-3}\right)$, followed by nurseries $\left(0.3 \mathrm{ng} \cdot \mathrm{m}^{-3}\right)$ and finally apartments $\left(0.06 \mathrm{ng} \cdot \mathrm{m}^{-3}\right)$.

TBBPA remained below the LOQ of $0.14 \mathrm{ng} \cdot \mathrm{m}^{-3}$. Indeed, this compound has low volatility with a vapour pressure at $25{ }^{\circ} \mathrm{C}$ of $1.810^{-6} \mathrm{~Pa}$ (TOXNET, 2014). Therefore, no particular trend could be found for this compound, consistent with the literature. The concentrations measured in the indoor air of houses and garages in the USA and of houses and offices in Japan and the UK are in the range of 10-20 pg.m ${ }^{-3}$ (Abdallah et al., 2008; Batterman et al., 2009; Inoue et al., 2006; Takigami et al., 2009).

\section{Compounds from combustion processes}

PAH concentrations, reported as $\sum 8 \mathrm{PAHs}$, showed no significant variations among the types of building (office: $0.91 \pm 0.81 \mathrm{ng} \cdot \mathrm{m}^{-3}$, apartment: $1.05 \pm 2.14 \mathrm{ng} \cdot \mathrm{m}^{-3}$; nursery: $0.58 \pm 0.41 \mathrm{ng} \cdot \mathrm{m}^{-3}$ ).

Among PAHs, FLU and PHE were the most abundant in the three buildings, and the highest concentrations were found in the nursery $(p<0.05)$. The nursery is located on the ground floor, while the office and apartment are on the fourth and second floors, respectively. In Italy, indoor PAH concentrations on the lower floors of buildings exceeded the concentrations at higher levels when heating was off, outdoor vehicle exhaust being the dominant source. In contrast, the levels were equal or even lower on the lower floors when the heating was on. The vertical gradient of indoor PAHs between different floors was within a factor of 2 (Menichini et al., 2007). Moreover, Krugly et al. (2014) reported a remarkably high PHE concentration in a kindergarten (up to 115 $\mathrm{ng} \cdot \mathrm{m}^{-3}$ ) compared to school sites. They attributed this result to the site location in the city centre with intensive road traffic in the vicinity and frequent opening of windows for ventilation.

Despite the possible emissions from cooking activities, the apartment and the nursery showed $\mathrm{BaP}$ concentrations lower than the office, with mean values of $0.029 \pm 0.019$ and $0.006 \pm 0.001$ ng. $\mathrm{m}^{-3}$, respectively, vs. $0.108 \pm 0.081 \mathrm{ng} \cdot \mathrm{m}^{-3}$ for the office $(p<0.05)$. In contrast, higher BaP 
concentrations linked to cooking that ranged from 6.1 to 24 ng. $\mathrm{m}^{-3}$ were found in Chinese dwellings (Zhu and Wang, 2003). The BaP concentrations in the nursery were lower than those observed in the USA: from 0.054 to $0.156 \mathrm{ng} \cdot \mathrm{m}^{-3}$ (Wilson et al., 2001). In this study, the TSP concentrations could not explain the variability of BaP concentration between indoor sites.

In the UK, Delgado-Saborit et al. (2011) focused on the particulate phase of PAHs and found no differences between a wide range of dwelling and work environments. The median PHE concentrations in houses $(n=162)$ and offices $(n=30)$ were 0.34 and $0.22 n g . m^{-3}$, respectively. Mean BaP concentrations of 0.09 ng. $\mathrm{m}^{-3}$ were reported for both environments.

The literature reports a wide range of environmental contexts and hypotheses on PAH occurrence in indoor air, but it excludes all emissions other than combustion processes. However, other modes should not be neglected given that PAHs may occur as traces in many products other than fossil fuels. Some of the major companies manufacturing computer hardware mention on their websites the accidental occurrence of PCBs, PBDEs, TBBPA and some PAHs in their products, at levels below the limits prescribed by European environmental and health regulations (HP, 2015; DELL, 2015). This is an example of potential emission sources at room temperature which might contribute to differences in SVOC composition and concentration in indoor air, since most plastics are derived from petroleum products.

\subsection{Indoor versus outdoor concentrations}

The indoor pattern was close to that observed in the outdoor environment by Teil et al. (2016)

(Figure 1, Table 1, SI-Appendix 6). The indoor air concentrations of PAE compounds, except DEHP, were significantly higher (from 23 to 40 times) than the outdoor air concentrations (Table 1, SIAppendix 6). The opposite was found for outdoor concentrations of DEHP, which were similar to those of the office and the apartment and only half that of the nursery. These discrepancies might be explained by the type of sources of these compounds. DEHP originates from indoor and outdoor passive volatilization, whereas other PAEs such as DEP and DiBP are emitted indoors by 
materials and consumer products (Teil t aI, 2006). Generall, it is a

materials and consumer products (Teil et al., 2006). Generally, it is agreed that outdoor sources of particulate PAEs, such as tyre wear, are minor contributors to indoor contamination (Rakkestad et al., 2007). AP concentrations in indoor air were eight to 80 times higher than the outdoor concentrations (Table 1), indicating that indoor sources are important.

Indoor PCB concentrations were generally up to ten times higher than those measured in the outdoor air in the same area (Teil et al., 2016). Studies of PCB contamination have shown indoor air concentrations to be at least ten and up to 100000 times higher than outdoor air concentrations (Rudel and Perovich, 2009).

Indoor air concentrations of PAHs tend to exceed outdoor air concentrations for compounds containing up to four rings. For molecules containing five rings and more, the trend indicates that the greatest concentrations are outdoors. Similar results were found in homes in the USA; however, acenaphthene (ACE), FLU, FTH and PHE appear to have significant outdoor sources and suggest a combination of indoor and outdoor sources (Rudel et al., 2010).

Overall, the SVOCs showed higher indoor concentrations, except for the PAHs, suggesting primarily indoor sources. The different SVOC sources were confirmed by Spearman coefficients, which showed strong correlations between APs, parabens and PAEs. No correlation was found for PAHs (Table 3).

\subsection{Indoor air concentrations depending on the season}

The variation of indoor concentrations (Table 1) was evaluated at two different outdoor temperatures: a $15.4{ }^{\circ} \mathrm{C}$ mean daily value in the non-heating period and $4{ }^{\circ} \mathrm{C}$ in the heating period, while the mean annual indoor temperature ranged from 19.3 to $23.6^{\circ} \mathrm{C}$ (SI-Appendix 2).

The PBDE concentrations exhibited no seasonal variation, except for that of BDE209 inside the office. For this compound, Hazrati and Harrad (2006) reported that although concentrations in warmer months usually exceeded those in colder months, seasonal variability in buildings appears less significant than that observed for outdoor air. Parabens remained steady in the office and the 
nursery, related to a similar use of cleaning produCts, whereas the a

nursery, related to a similar use of cleaning products, whereas the apartment displayed a 2.5 -fold lower concentration during the heating season compared to the non-heating season.

No seasonal variation was observed for PAEs except in the apartment. The low temperature variation in the 3 indoor sites (maximum $2^{\circ} \mathrm{C}$ in the nursery) might explain this observation. The significant increases of indoor PAE concentrations reported in the USA were observed for far higher temperature increase $\left(10^{\circ} \mathrm{C}\right)$ (Bi et al.,2015; Liang and $\left.\mathrm{Xu} ; 2014 \mathrm{~b}\right)$.

AP concentrations were slightly lower in the heating period in the office and the nursery, and in the apartment, they were threefold lower in the non-heating season compared to the heating season. For these three chemical families, considering a steady indoor temperature in the three buildings and similar occupant behaviour in terms of window opening in the heating and nonheating seasons, the absence of a statistically significant seasonal variation argues in favour of a contaminant originating mainly from indoor sources rather than outdoor sources (Table 1).

A clear seasonal variation was observed for $\mathrm{BPA}, \mathrm{PCBs}$ and $\mathrm{PAHs}$ whatever the indoor site (Table 1). BPA displayed temporal variation, with a fourfold lower concentration in the heating period compared to the non-heating period.

The PCB concentrations in the office showed the least seasonal variation, with a nearly twofold lower concentration in the heating period (1.91 vs $\left.1.05 \mathrm{ng} \cdot \mathrm{m}^{-3}\right)$. In the apartment and the nursery, air concentrations decreased from 0.82 to $0.27 \mathrm{ng} \cdot \mathrm{m}^{-3}$ and from 3.23 to $0.28 \mathrm{ng} \cdot \mathrm{m}^{-3}$ in the heating and non-heating periods, respectively. Thus, the seasonal variability of PCB indoor concentrations seems higher than the variability between each site, whereas the temperature inside the buildings remained steady, suggesting a potential outdoor source and higher volatilization at ambient temperatures in the urban area. Indeed, seasonal variations of indoor PCB concentrations were reported, the winter period presenting systematically lower concentrations than the summer period (Waeber et al., 2012). However, in Birmingham (UK), the 
ACCEPTED MANUSCRIPT

seasonal variability of indoor contamination in offices, homes and public environments appeared lower than that of outdoor air (Hazrati and Harrad, 2006).

In contrast to the other SVOCs, the seasonal variability of indoor PAH concentration was relatively high. Thus, the indoor concentrations increased during the heating period for all PAHs. The variations observed were mainly the result of PAH emissions from domestic heating activities in winter. Indeed, outdoor air concentrations, measured as $\Sigma 8 \mathrm{PAHs}$, were twice as high in the heating season as in the non-heating season. In 2012, domestic heating accounted for approximately $74 \%$ of the emissions from combustion processes (CITEPA, 2014). Data from the local ambient air monitoring network, Airparif, showed that from January 2011 to December 2012, wide discrepancies occurred due to seasonal PAH variations, with only minor concentrations from April to October. Moreover, the contribution of residential areas and domestic heating to $\mathrm{PAH}$ levels in the urban centre in winter was shown, whereas during the non-heating period, only background PAH levels corresponding to motorway traffic were observed. The seasonal pattern of indoor air contamination results from that of outdoor contamination (Airparif, 2013). In Rome (Italy), daily concentrations of BaP ranged from 0.5 (heating off) to $4.6 \mathrm{ng} \cdot \mathrm{m}^{-3}$ (heating on) in indoor (apartments) and from 0.6 (heating off) to $1.5 \mathrm{ng} \cdot \mathrm{m}^{-3}$ (heating on) in outdoor (sample on the roof) (Menichini et al., 2007). Thus, the indoor air exhibited higher concentrations than outdoor air during the heating season.

\subsection{Gaseous/particulate phase partitioning}

APs and parabens were found almost exclusively in the gaseous phase, ranging from 85 to $97 \%$ and from 86 to $100 \%$ of air concentrations, respectively, regardless of the building and the season. Additionally, PCBs were almost exclusively in the gaseous phase, from 73 to $100 \%$, in the non-heating period and from 33 to $100 \%$ in the heating period.

PBDEs were mainly in the particulate phase with a mean percentage ranging from 40 to $75 \%$, except BDE 28, which was exclusively in the gaseous phase. Unexpectedly, BDE 209 was detected 
mainly in the gaseous phase, but its cOncentration was often aroun

mainly in the gaseous phase, but its concentration was often around its LOQ. BDE-209 was only rarely detected in the gaseous phase only and never in the particulate phase of indoor air in 30 French dwellings (Blanchard et al. 2014).

For PAEs, except for BBzP, DEHP and DnOP, the gaseous phase accounted for $>90 \%$ of air concentrations. In contrast, DEHP was prevalent in the particulate phase, accounting for $63 \%$ in the non-heating period and $84 \%$ in the heating period. BPA was mainly in the particulate phase (65-72\%), as previously observed by Blanchard et al. (2014).

Similarly, less volatile compounds such as the heavy PAHs, were almost exclusively in the particulate phase in the heating period. In the indoor air of preschools in Lithuania, similar PAH distributions were found with 100 and $80 \%$ of the two- and three-ring compounds, respectively, in the gaseous phase, whereas 100 and $62 \%$ of the five- and six-ring compounds, respectively, were in the particulate phase (Krugly et al., 2014). The high proportion of PAHs (85\%) in the gaseous phase of indoor air from a preschool in Portugal clearly showed that an adequate assessment of indoor PAH concentrations and the associated exposure requires consideration of the gaseous compounds, which are neglected in most studies (Oliveira et al., 2014).

Partitioning between the gaseous and particulate phases is shown on Figure 2 and in SIAppendix 7. Figure 2a represents the relationship between vapor pressure and gas/particle partitioning during the non-heating period to avoid the effects associated with combustion processes. The relationship was a non-linear regression $\left(r^{2}=0.596, p<0.001\right)$ with the following equation (eq. 1):

$\%$ gaseous phase $=103.97 /(1+\operatorname{Exp}(-4.08-0.91 * \log ($ vapor pressure $)))($ equation 1$)$

This equation is consistent with Junge-Pankow adsorption model (Harner and Bidleman, 1998).

For the heating period, the variation of gaseous phase vs. vapor pressure showed a similar model equation than during the non heating period (fig. $2 \mathrm{~b}$ and eq. 2 ). 


\section{$\%$ gaseous phase $=96 /(1+\operatorname{Exp}(-5,15-1,42 * \log ($ vapor pressure $))) .($ equation 2$)$}

Compounds with vapor pressure higher than $110^{-3} \mathrm{~Pa}$ exhibited a percentage in the gaseous phase greater than $80 \%$ except BDE 209 and hepta-hexa PCBs, which were mainly in the gaseous phase while their vapor pressure was lower than $110^{-3} \mathrm{~Pa}$. Indoor temperatures $\left(20^{\circ} \mathrm{C}\right)$ and low indoor concentrations of TSP $\left(25 \mu \mathrm{g} \cdot \mathrm{m}^{-3}\right)$ favoured this general predominance of SVOCs in the gaseous phase. Moreover, a seasonal influence on partitioning was observed, except for parabens, PCBs and the lowest molecular-weight PBDEs and APs. The other compounds were higher in the particulate phase during the heating period.

The Kp values showed a variation trend opposite to that of the gaseous phase concentrations between the 2 periods ie an increase of the Kp during the heating period for the heavy compounds with low vapor pressures $\left(<10^{-3} \mathrm{~Pa}\right)$. However, the difference of temperature between the heating and the non-heating periods was only $2{ }^{\circ} \mathrm{C}$ in the nursery and $1{ }^{\circ} \mathrm{C}$ for the 2 other sites.

The $\mathrm{Kp}$ values seemed rather related to the physico-chemical characteristics of the compounds (molecular weight, vapor pressure), as discussed by Wei et al. (2016), than to the particle origin (indoor/outdoor).

\section{Conclusion}

This study underlines the ubiquity of SVOCs in indoor air. A wide spectrum of 58 semi-volatile organic compounds was quantified in air, even at trace levels, by a device using a medium-volume sampler and multi-residue analysis.

Indoor air contamination by the different SVOC families was consistent with the sources, production, uses and regulation of compounds. The concentrations and patterns found here were consistent with literature. Among the contaminants studied, PAEs prevailed, whatever the location and the time of year. 
Our results highlighted, for the first time, the major occurrence of both APs and parabens in the gaseous phase and confirmed the gas-phase prevalence of most PAEs, light PAHs and PCBs.

For all SVOCs the nursery displayed higher concentrations than the apartment and office. The highest indoor air contamination in the nursery might be related to abundant synthetic materials and extensive use of detergents and disinfectants, contributing to toddlers' high exposure through inhalation.

For PBDEs, parabens and APs, the absence of temporal variation and the prevailing indoor as compared to outdoor air concentrations, indicates that they predominate indoors. For PCBs, markedly greater variability was found for season than for the indoor location, which is in line with these compounds originating partially outdoors in urban areas. Moreover, the emission of PAEs and PAHs by volatilization or combustion processes at ambient temperature in outdoor environments might affect indoor air quality. The predominance of the gaseous phase in the occurrence of pollutants indoor was shown, except for DEHP and BaP.

These data could also be useful for both inputs and validation of models for indoor environmental fate and human exposure.

\section{Conflict of interest}

The authors declare that they have no conflict of interest.

\section{Acknowledgements}

This work was funded by the "Programme National de Recherche sur les Perturbateurs

Endocriniens" (PNRPE). Financial support was received from the ADEME (Grant no. C09P072) and 
Annie Desportes throughout this study is gratefully acknowledged.

References

561

562

563

564

565

566

567

568

569

570

571

572

573

574

575

576

577

578

579

580

581

582

583

584

585

586

587

588

589

590

591

592

593

594

595

596

597

598

599

600

601

Abdallah, M.A.-E., Harrad, S., Covaci, A., 2008. Hexabromocyclododecanes and Tetrabromobisphenol-A in Indoor Air and Dust in Birmingham, UK: Implications for Human Exposure. Environ. Sci. Technol. 42, 6855-6861. doi:10.1021/es801110a

AFNOR, 2003. Stationary source emissions - Sampling and measurement of polycyclic aromatic hydrocarbons and tars at emission, Norme NF X43-329. Association Française de Normalisation, $37 p$.

Airparif, 2013. Pollution atmosphérique au Benzo(a)pyrène et autres Hydrocarbures Aromatiques Polycycliques (HAP) - cas de la région lle-de-France. URL www.airparif.asso.fr

Allen J., Sarofim A. and Smith K.,1997. A critical evaluation of two proposed atmospheric partitioning mechanisms, Adsorption and absorption, using atmospheric data for polycyclic aromatic hydrocarbons. Journal of Aerosol Science 28, S335-\$336.

Alliot, F., Moreau-Guigon, E., Bourges, C., Desportes, A., Teil, M.-J., Blanchard, M., Chevreuil, M., 2014. A multi-residue method for characterization of endocrine disruptors in gaseous and particulate phases of ambient air. Atmos. Environ. 92, 1-8. doi:10.1016/j.atmosenv.2014.02.044

Anezaki, K., Kannan, N., Nakano, T., 2015. Polychlorinated biphenyl contamination of paints containing polycyclic- and Naphthol AS-type pigments. Environ. Sci. Pollut. Res. 22, 14478-14488. doi:10.1007/s11356-014-2985-6

Batterman, S.A., Chernyak, S., Jia, C., Godwin, C., Charles, S., 2009. Concentrations and Emissions of Polybrominated Diphenyl Ethers from US Houses and Garages. Environ. Sci. Technol. 43, 26932700. doi:10.1021/es8029957

Bergh, C., Torgrip, R., Emenius, G., Östman, C., 2011. Organophosphate and phthalate esters in air and settled dust - a multi-location indoor study: Organophosphate and phthalate esters in air and settled dust. Indoor Air 21, 67-76. doi:10.1111/j.1600-0668.2010.00684.x

Bezares-Cruz, J., Jafvert, C.T., Hua, I., 2004. Solar Photodecomposition of Decabromodiphenyl Ether: Products and Quantum Yield. Environ. Sci. Technol. 38, 4149-4156. doi:10.1021/es0496080

Bi, C., Liang, Y., Xu, Y. (2015). Fate and transport of phthalates in indoor environments and the influence of temperature: a case study in a test house. Environmental Science \& Technology, 49, 9574-9681.

Blanchard, O., Glorennec, P., Mercier, F., Bonvallot, N., Chevrier, C., Ramalho, O., Mandin, C., Bot, B.L., 2014. Semivolatile Organic Compounds in Indoor Air and Settled Dust in 30 French Dwellings. Environ. Sci. Technol. 48, 3959-3969. doi:10.1021/es405269q

Błędzka, D., Gromadzińska, J., Wąsowicz, W., 2014. Parabens. From environmental studies to human health. Environ. Int. 67, 27-42. doi:10.1016/j.envint.2014.02.007

Bonnet C., Kupper T., Alencastro L.F.d., Grandjean D. and Tarradellas J., 2004. Détermination des diphénylethers polybromés (PBDE) dans les boues d'épuration provenant du réseau d'observation SEA. Rapport de l'Office fédéral de l'environnement, des forêts et du paysage (OFEFP) : Division protection des eaux et pêche. URL http://www.sea.eawag.ch/inhalt/sites/projekte/pdf/B_PBDE_2004.pdf

Bonvallot, N., Mandin, C., Mercier, F., Le Bot, B., Glorennec, P., 2010. Health ranking of ingested semivolatile organic compounds in house dust: an application to France. Indoor Air 20, 458-472. doi:10.1111/j.1600-0668.2010.00667.x 
Brunelle, D.J., 2002. Polycarbonates, in: Encyclopedia of Polymer Science and Technology. John Wiley \& Sons, Inc.

BSEF, 2012. Deca-BDE, Factsheet Brominated Flame Retardant. URL http://www.bsef.com/uploads/Deca_factsheet_25-10-2012.pdf (accessed 1.26.16).

Burkhard L.P., Armstrong D.E. and Andren A.W., 1985. Henry's law constants for the polychlorinated biphenyls, Environ. Sci. Technol., 19, 590-596.

Casas, M., Chevrier, C., Hond, E.D., Fernandez, M.F., Pierik, F., Philippat, C., Slama, R., Toft, G., Vandentorren, S., Wilhelm, M., Vrijheid, M., 2013. Exposure to brominated flame retardants, perfluorinated compounds, phthalates and phenols in European birth cohorts: ENRIECO evaluation, first human biomonitoring results, and recommendations. Int. J. Hyg. Environ. Health 216, 230-242. doi:10.1016/j.ijheh.2012.05.009

CITEPA, 2014. Inventaire des émissions de polluants atmosphériques et de gaz à effet de serre en France Format SECTEN. URL http://www.citepa.org/images/III1_Rapports_Inventaires/secten_avril2014_sec.pdf (accessed 6.8.15).

Cladiere, M., Gasperi, J., Lorgeoux, C., Bonhomme, C., Rocher, V., Tassin, B., 2013. Alkylphenolic compounds and bisphenol A contamination within a heavily urbanized area: case study of Paris. Environ. Sci. Pollut. Res. 20, 2973-2983. doi:10.1007/s11356-012-1220-6

Delgado-Saborit, J.M., Stark, C., Harrison, R.M., 2011. Carcinogenic potential, levels and sources of polycyclic aromatic hydrocarbon mixtures in indoor and outdoor environments and their implications for air quality standards. Environ. Int. 37, 383-392. doi:10.1016/j.envint.2010.10.011

DELL, 2015. Materials Restricted for Use - ENV0424, 27p. URL

http://www.dell.com/downloads/global/corporate/environ/restricted_materials_guid.pdf (accessed 2.8.16).

de Wit, C.A., Björklund, J.A., Thuresson, K., 2012. Tri-decabrominated diphenyl ethers and hexabromocyclododecane in indoor air and dust from Stockholm microenvironments 2: Indoor sources and human exposure. Environ. Int. 39, 141-147. doi:10.1016/j.envint.2011.11.001

Directive2003/11/EC, 2003. Directive of the European Parliament and of the Council of 6 February 2003 relating to restrictions on the marketing and use of certain dangerous substances and preparations (pentabromodiphenyl ether, octabromo-diphenyl ether). URL http://eurlex.europa.eu/LexUriServ/LexUriServ.do?uri=OJ:L:2003:042:0045:0046:EN:PDF

Directive 2004/93/EC, 2004. Directive 2004/93/EC of 21 September 2004 amending Council Directive 76/768/EEC for the purpose of adapting its Annexes II and III to technical progress(Text with EEA relevance). URL http://eur-lex.europa.eu/legal-content/EN/TXT/?uri=celex\%3A32004L0093

Directive 2005/80/EC, 2005. Directive 2005/80/EC of 21 November 2005 amending Council Directive 76/768/EEC, concerning cosmetic products, for the purposes of adapting Annexes II and III thereto to technical progress. URL http://eur-lex.europa.eu/legalcontent/EN/TXT/?uri=uriserv:OJ.L_.2005.303.01.0032.01.ENG

Directive 2005/84/EC, 2005. Directive 2005/84/EC of the European Parliament and of the Council of 14 December 2005 relating to restrictions on the marketing and use of certain dangerous substances and preparations (phthalates in toys and childcare articles). URL http://eur-lex.europa.eu/legalcontent/EN/TXT/?uri=URISERV:I32033

European Commission, 2014. Union's Implementation Plan for the Stockholm Convention on Persistent Organic Pollutants. URL http://eur-lex.europa.eu/legalcontent/EN/TXT/PDF/?uri=CELEX:52014SC0172\&from=EN (accessed 10.23.15).

Ferreira M.M., 2001. Polycyclic aromatic hydrocarbons: a QSPR study. Chemosphere, 44, 125-146.

Fromme, H., Körner, W., Shahin, N., Wanner, A., Albrecht, M., Boehmer, S., Parlar, H., Mayer, R., Liebl, B., Bolte, G., 2009. Human exposure to polybrominated diphenyl ethers (PBDE), as evidenced by data from a duplicate diet study, indoor air, house dust, and biomonitoring in Germany. Environ. Int. 35, 1125-1135. doi:10.1016/j.envint.2009.07.003

Gaudin, R., Marsan, P., Ndaw, S., Robert, A., Ducos, P., 2011. Biological monitoring of exposure to di(2ethylhexyl) phthalate in six French factories: a field study. Int. Arch. Occup. Environ. Health 84, 523531. doi:10.1007/s00420-010-0566-7 


\section{ACCEPTED MANUSCRIPT}

Granier, L., Chevreuil, M., 1991. Automobile traffic: A source of PCBs to the atmosphere. Chemosphere 23, 785-788. doi:10.1016/0045-6535(91)90082-0

Granier, L.K., Chevreuil, M., 1997. Behaviour and spatial and temporal variations of polychlorinated biphenyls and lindane in the urban atmosphere of the Paris area, France. Atmos. Environ. 31, 37873802.

Guo, Y., Wang, L., Kannan, K., 2013. Phthalates and Parabens in Personal Care Products From China: Concentrations and Human Exposure. Arch. Environ. Contam. Toxicol. 66, 113-119. doi:10.1007/s00244-013-9937-x

Harner, T., Bidleman, T.F., 1998. Octanol-air partition coefficient for describing particle/gas partitioning of aromatic compounds in urban air. Environmental Science \& Technology 32, 1494-1502.

Hazrati, S., Harrad, S., 2006. Causes of Variability in Concentrations of Polychlorinated Biphenyls and Polybrominated Diphenyl Ethers in Indoor air. Environ. Sci. Technol. 40, 7584-7589. doi:10.1021/es0617082

Heinzow, B., Mohr, S., Ostendorp, G., Kerst, M., Körner, W., 2007. PCB and dioxin-like PCB in indoor air of public buildings contaminated with different $\mathrm{PCB}$ sources - deriving toxicity equivalent concentrations from standard PCB congeners. Chemosphere 67, 1746-1753. doi:10.1016/j.chemosphere.2006.05.120

Heudorf, U., Angerer, J., 2001. Internal exposure to PAHs of children and adults living in homes with parquet flooring containing high levels of PAHs in the parquet glue. Int. Arch. Occup. Environ. Health 74, 91-101. doi:10.1007/s004200000214

HP, 2015. General Specification for the Environment (GSE). 85p. URL http://h20195.www2.hp.com/V2/GetDocument.aspx?docname=c04932490 (accessed 2.8.16).

IEPA/APC, 1985. Southeast Chicago Air Quality: A Plan for the Evaluation of PCBs (Polychlorinated biphenyls), IEPA/APC/85-003. Illinois State Environmental Protection Agency, Springfield. Div. of Air Pollution Control, 124p.

Inoue, K., Yoshida, S., Nakayama, S., Ito, R., Okanouchi, N., Nakazawa, H., 2006. Development of stable isotope dilution quantification liquid chromatography-mass spectrometry method for estimation of exposure levels of bisphenol A, 4-tert-octylphenol, 4-nonylphenol, tetrabromobisphenol A, and pentachlorophenol in indoor air. Arch. Environ. Contam. Toxicol. 51, 503-508. doi:10.1007/s00244005-0236-z

Krugly, E., Martuzevicius, D., Sidaraviciute, R., Ciuzas, D., Prasauskas, T., Kauneliene, V., Stasiulaitiene, I., Kliucininkas, L., 2014. Characterization of particulate and vapor phase polycyclic aromatic hydrocarbons in indoor and outdoor air of primary schools. Atmos. Environ. 82, 298-306. doi:10.1016/j.atmosenv.2013.10.042

Laborie, S., Moreau-Guigon, E., Alliot, F., Desportes, A., Oziol, L., Chevreuil, M., 2016. A new analytical protocol for the determination of 62 endocrine-disrupting compounds in indoor air. Talanta 147, 132-141. doi:10.1016/j.talanta.2015.09.028

Liang, Y., Xu, Y. (2014a). Improved method for measuring and characterizing phthalate emissions from building materials and its application to exposure assessment. Environmental Science \& Technology, 48, 4475-4484.

Liang, Y., Xu, Y. (2014b). Emission of phthalates and phthalate alternatives from vinyl flooring and crib mattress covers: The influence of temperature. Environmental Science \& Technology, 48, 1422814237.

Lu, H., Zhu, L., Chen, S., 2008. Pollution level, phase distribution and health risk of polycyclic aromatic hydrocarbons in indoor air at public places of Hangzhou, China. Environ. Pollut. 152, 569-575. doi:10.1016/j.cnvpol.2007.07.005

Mackay D, 1980. Solubility, partition coefficient, volatility and evaporation rates. The Handbook of Environmental Chemistry, 2, 31-45.

Mackay D., Shiu W.-Y., Ma K.-C. and Lee S. C., 2006. Handbook of Physical-Chemical Properties and Environmental Fate for Organic Chemicals, Second Edition; CRC Press. 
Mandin, C., Mercier, F., Ramalho, O., Lucas, J.-P., Gilles, E., Blanchard, O., Bonvallot, N., Glorennec, P., Le Bot, B., 2016. Semi-volatile organic compounds in the particulate phase in dwellings: A nationwide survey in France. Atmospheric Environment 136, 82-94. doi:10.1016/j.atmosenv.2016.04.016

Menichini, E., lacovella, N., Monfredini, F., Turrio-Baldassarri, L., 2007. Relationships between indoor and outdoor air pollution by carcinogenic PAHs and PCBs. Atmos. Environ. 41, 9518-9529. doi:10.1016/j.atmosenv.2007.08.041

Ministry of the Environment (Government of Japan), 2014. Profiles of the Initial Environmental Risk Assessment of Chemicals. URL https://www.env.go.jp/en/chemi/chemicals/profile_erac/profile7/pf2-02.pdf (accessed Oct 30, 2014).

Nordic Institute of Sustainable Products and Environmental Chemistry and Toxicology, 2013. Health risks of PCB in the indoor climate in Denmark - background for setting recommended action levels, p. 22.

Oliveira, M., Slezakova, K., Delerue-Matos, C., Pereira, M.C., Morais, S., 2014. Polycyclic aromatic hydrocarbons: levels and phase distributions in preschool microenvironment. Indoor Air n/a-n/a. doi:10.1111/ina.12164

Peijnenburg, W.J.G.M., Struijs, J., 2006. Occurrence of phthalate esters in the environment of the Netherlands. Ecotoxicol. Environ. Saf. 63, 204-215. doi:10.1016/j.ecoenv.2005.07.023

Rakkestad, K.E., Dye, C.J., Yttri, K.E., Holme, J.A., Hongslo, J.K., Schwarze, P.E., Becher, R., 2007. Phthalate levels in Norwegian indoor air related to particle size fraction. J. Environ. Monit. 9, 1419. doi:10.1039/b709947a

Ramirez N., Marce R.M., Borrull F., 2010. Development of a thermal desorption-gas chromatography-mass spectrometry method for determining personal care products in air. J Chromatogr A 1217, 44304438.

Reach, 2015. Candidate List of substances of very high concern for Authorisation - ECHA [WWW Document]. URL http://echa.europa.eu/web/guest/candidate-list-table\#download (accessed 1.26.16).

Rodenburg, L.A., Guo, J., Du, S., Cavallo, G.J., 2010. Evidence for Unique and Ubiquitous Environmental Sources of 3,3'-Dichlorobiphenyl (PCB 11). Environ. Sci. Technol. 44, 2816-2821. doi:10.1021/es901155h

Romagnoli, P., Balducci, C., Perilli, M., Gherardi, M., Gordiani, A., Gariazzo, C., Gatto, M.P., Cecinato, A., 2014. Indoor PAHs at schools, homes and offices in Rome, Italy. Atmos. Environ. 92, 51-59. doi:10.1016/j.atmosenv.2014.03.063

Rudel, R.A., Camann, D.E., Spengler, J.D., Korn, L.R., Brody, J.G., 2003. Phthalates, alkylphenols, pesticides, polybrominated diphenyl ethers, and other endocrine-disrupting compounds in indoor air and dust. Environ. Sci. Technol. 37, 4543-4553. doi:10.1021/es0264596

Rudel, R.A., Dodson, R.E., Perovich, L.J., Morello-Frosch, R., Camann, D.E., Zuniga, M.M., Yau, A.Y., Just, A.C., Brody, J.G., 2010. Semivolatile Endocrine-Disrupting Compounds in Paired Indoor and Outdoor Air in Two Northern California Communities. Environ. Sci. Technol. 44, 6583-6590. doi:10.1021/es100159c

Rudel, R.A., Perovich, L.J., 2009. Endocrine disrupting chemicals in indoor and outdoor air. Atmos. Environ. 43, 170-181. doi:10.1016/j.atmosenv.2008.09.025

Saito, I., Onuki, A., Seto, H., 2004. Indoor air pollution by alkylphenols in Tokyo. Indoor Air 14, 325-332. doi:10.1111/j.1600-0668.2004.00250.x

Sanchez-Prado, L., Llompart, M., Lamas, J.P., Garcia-Jares, C., Lores, M., 2011. Multicomponent analytical methodology to control phthalates, synthetic musks, fragrance allergens and preservatives in perfumes. Talanta 85, 370-379. doi:10.1016/j.talanta.2011.03.079

Shen, H., Huang, Y., Wang, R., Zhu, D., Li, W., Shen, G., Wang, B., Zhang, Y., Chen, Y., Lu, Y., Chen, H., Li, T., Sun, K., Li, B., Liu, W., Liu, J., Tao, S., 2013. Global Atmospheric Emissions of Polycyclic Aromatic Hydrocarbons from 1960 to 2008 and Future Predictions. Environ. Sci. Technol. 47, 6415-6424. doi:10.1021/es400857z

Staples, C.A., Peterson, D.R., Parkerton, T.F., Adams, W.J., 1997. The environmental fate of phthalate esters: A literature review. Chemosphere 35, 667-749. doi:10.1016/S0045-6535(97)00195-1 
Staples C.A., Dome P.B., Klecka G.M., Oblock S.T., Harris L.R., 1998. A review of the environmental fate, effects and exposures of bisphenol A. Chemosphere 36, 2149 - 2173.

Takigami, H., Suzuki, G., Hirai, Y., Sakai, S., 2009. Brominated flame retardants and other polyhalogenated compounds in indoor air and dust from two houses in Japan. Chemosphere 76, 270-277. doi:10.1016/j.chemosphere.2009.03.006

Teil, M.J., Blanchard, M., Chevreuil, M., 2006. Atmospheric fate of phthalate esters in an urban area (ParisFrance). Sci. Total Environ. 354, 212-223. doi:10.1016/j.scitotenv.2004.12.083

Teil, M.J., Moreau-Guigon, E., Blanchard, M., Alliot, F., Gasperi, J., Cladière, M., Mandin, C., Moukhtar, S., Chevreuil, M., 2016. Endocrine disrupting compounds in gaseous and particulate outdoor air phases according to environmental factors. Chemosphere 146, 94-104.

Thuresson, K., Björklund, J.A., de Wit, C.A., 2012. Tri-decabrominated diphenyl ethers and hexabromocyclododecane in indoor air and dust from Stockholm microenvironments 1: Levels and profiles. Sci. Total Environ. 414, 713-721. doi:10.1016/j.scitotenv.2011.11.016

TOXNET 2014. TOXNET database, URL http://toxnet.nlm.nih.gov/ (accessed Oct 30, 2014)

Tran, T.M., Kannan, K., 2015. Occurrence of Phthalate Diesters in Particulate and Vapor Phases in Indoor Air and Implications for Human Exposure in Albany, New York, USA. Arch. Environ. Contam. Toxicol. 68, 489-499. doi:10.1007/s00244-015-0140-0

Viñas, P., Campillo, N., Pastor-Belda, M., Oller, A., Hernández-Córdoba, M., 2015. Determination of phthalate esters in cleaning and personal care products by dispersive liquid-liquid microextraction and liquid chromatography-tandem mass spectrometry. J. Chromatogr. A 1376, 18-25. doi:10.1016/j.chroma.2014.12.012

Waeber, R., Kohler, M., Schmid, P., Zennegg, M., Seiler, C., 2012. Analyse des PCB à l'intérieur des bâtiments, Informations et recommandations. Federal Office Public Health. URL www.bag.admin.ch/themen/chemikalien/00228/00512/index.html?

Wania F. and Dugani C.B, 2003. Assessing the long-range transport potential of polybrominated diphenyl ethers: a comparison of four multimedia models Environ. Toxicol. Chem 22, $1252-1261$.

Wei, W., Mandin, C., Blanchard, O., Mercier, F., Pelletier, M., Le Bot, B., Glorennec, P., Ramalho, O., 2016. Distributions of the particle/gas and dust/gas partition coefficients for seventy-two semi-volatile organic compounds in indoor environment. Chemosphere 153, 212-219. doi:10.1016/j.chemosphere.2016.03.007

Weschler, C.J., 2009. Changes in indoor pollutants since the 1950s. Atmos. Environ. 43, 153-169. doi:10.1016/j.atmosenv.2008.09.044

Salthammer, T., Fromme, H., 2008. Partitioning of phthalates among the gas phase, airborne particles and settled dust in indoor environments. Atmos. Environ. 42, 1449-1460. doi:10.1016/j.atmosenv.2007.11.014

WHO, 2011. Toxicological and Health Aspects of Bisphenol A. Report of Joint FAO/WHO Expert Meeting 25 November 2010 and Report of Stakeholder Meeting on Bisphenol A 1 November 2010. Ottawa, Canada. URL http://whqlibdoc.who.int/publications/2011/97892141564274_eng.pdf (accessed 6.2.15).

Wilson, N.K., Chuang, J.C., Lyu, C., 2001. Levels of persistent organic pollutants in several child day care centers. J. Expo. Anal. Environ. Epidemiol. 11, 449-458. doi:10.1038/sj.jea.7500190

Wilson, N.K., Chuang, J.C., Morgan, M.K., Lordo, R.A., Sheldon, L.S., 2007. An observational study of the potential exposures of preschool children to pentachlorophenol, bisphenol-A, and nonylphenol at home and daycare. Environ. Res. 103, 9-20. doi:10.1016/j.envres.2006.04.006

Xu, Y., Cohen Hubal, E.A., Clausen, P.A., Little, J.C., 2009. Predicting residential exposure to phthalate plasticizer emitted from vinyl flooring: a mechanistic analysis. Environ. Sci. Technol. 43, 2374-2380.

Ying, G.-G., Williams, B., Kookana, R., 2002. Environmental fate of alkylphenols and alkylphenol ethoxylates-a review. Environ. Int. 28, 215-226.

Zhang, X., Arnot, J.A., Wania, F., 2014. Model for screening-level assessment of near-field Human exposure to neutral organic chemicals released indoors. Environ. Sci. Technol. 48, 12312-12319. doi:10.1021/es502718k 
Zhang, X., Diamond, M.L., Robson, M., Harrad, S., 2011. Sources, Emissions, and Fate of Polybrominated Diphenyl Ethers and Polychlorinated Biphenyls Indoors in Toronto, Canada. Environ. Sci. Technol.

45, 3268-3274. doi:10.1021/es102767g

Zhu, L.Z., Wang, J., 2003. Sources and patterns of polycyclic aromatic hydrocarbons pollution in kitchen air, China. Chemosphere 50, 611-618. doi:10.1016/S0045-6535(02)00668-9 
Table 1. Mean SVOC concentrations (gas + particles; $n g \cdot \mathrm{m}^{-3}$ ) for the non-heating and heating period, in indoor and outdoor air in centre of Paris. (LOQ: limit of quantification)

\begin{tabular}{|c|c|c|c|c|c|c|c|c|}
\hline \multirow[b]{2}{*}{$\mathrm{ng} \mathrm{m}^{-3}$} & \multicolumn{2}{|c|}{ Office $(n=6)$} & \multicolumn{2}{|c|}{ Apartment $(n=6)$} & \multicolumn{2}{|c|}{ Nursery $(n=6)$} & \multicolumn{2}{|c|}{ Outdoor (Teil et al., 2016) $(n=6)$} \\
\hline & Non-heating & Heating & Non-heating & Heating & Non-heating & Heating & Non-heating & Heating \\
\hline DMP & $16 \pm 11$ & $7.4 \pm 4.5$ & $53 \pm 37$ & $44 \pm 33$ & $180 \pm 69$ & $52 \pm 10$ & $0.31 \pm 0.28$ & $0.21 \pm 0.09$ \\
\hline DEP & $96 \pm 54$ & $49 \pm 8$ & $272 \pm 163$ & $63 \pm 49$ & $380 \pm 180$ & $160 \pm 19$ & $6.4 \pm 3.8$ & $6.8 \pm 2.3$ \\
\hline DiBP & $248 \pm 103$ & $152 \pm 24$ & $454 \pm 202$ & $42 \pm 22$ & $116 \pm 32$ & $251 \pm 24$ & $7.8 \pm 2.1$ & $8.0 \pm 1.1$ \\
\hline DnBP & $58 \pm 22$ & $63 \pm 6$ & $100 \pm 31$ & $32 \pm 23$ & $70 \pm 30$ & $75 \pm 21$ & $3.4 \pm 0.89$ & $1.3 \pm 0.094$ \\
\hline $\mathrm{BBz} P$ & $0.70 \pm 0.93$ & $2.2 \pm 0.000$ & $8.6 \pm 9.3$ & $0.63 \pm 0.000$ & $50 \pm 26$ & $88 \pm 21$ & $0.21 \pm 0.16$ & $0.072 \pm 0.061$ \\
\hline DEHP & $41 \pm 21$ & $23 \pm 9.1$ & $28 \pm 22$ & $6.2 \pm 5.9$ & $70 \pm 37$ & $67 \pm 11$ & $28 \pm 15$ & $19 \pm 4.0$ \\
\hline DnOP & $0.093 \pm 0.11$ & $2.0 \pm 2.3$ & $0.23 \pm 0.10$ & $0.031 \pm 0.053$ & $0.008 \pm 0.013$ & $4.7 \pm 7.8$ & $0.029 \pm 0.031$ & $<\mathrm{LOQ}$ \\
\hline ¿7PAES & $462 \pm 184$ & $328 \pm 36$ & $918 \pm 443$ & $207 \pm 150$ & $868 \pm 297$ & $725 \pm 74$ & $46 \pm 17$ & $22 \pm 3.4$ \\
\hline BPA & $0.72 \pm 0.66$ & $0.20 \pm 0.17$ & $0.68 \pm 0.56$ & $0.39 \pm 0.53$ & $1.1 \pm 1.3$ & $0.34 \pm 0.31$ & $0.14 \pm 0.084$ & $0.071 \pm 0.057$ \\
\hline OP & $1.7 \pm 0.66$ & $1.3 \pm 0.90$ & $1.0 \pm 0.35$ & $0.43 \pm 0.54$ & $6.6 \pm 3.1$ & $4.8 \pm 6.7$ & $0.23 \pm 0.099$ & $0.06 \pm 0.019$ \\
\hline 4-NP & $25 \pm 12$ & $15 \pm 8.3$ & $12 \pm 3.4$ & $4.2 \pm 4.7$ & $62 \pm 16$ & $36 \pm 31$ & $0.61 \pm 0.33$ & $0.56 \pm 0.095$ \\
\hline$\sum O P+4-N P$ & $26 \pm 13$ & $16 \pm 9.2$ & $14 \pm 3.7$ & $4.7 \pm 5.2$ & $69 \pm 19$ & $41 \pm 38$ & $0.84 \pm 0.38$ & $0.62 \pm 0.10$ \\
\hline MeP & $0.80 \pm 0.38$ & $1.1 \pm 0.54$ & $0.81 \pm 0.36$ & $0.22 \pm 0.25$ & $2.21 \pm 0.29$ & $1.5 \pm 0.29$ & $0.038 \pm 0.029$ & $0.062 \pm 0.035$ \\
\hline EtP & $0.14 \pm 0.055$ & $0.073 \pm 0.002$ & $0.074 \pm 0.032$ & $0.022 \pm 0.024$ & $0.36 \pm 0.11$ & $0.26 \pm 0.045$ & $0.012 \pm 0.004$ & $0.011 \pm 0.009$ \\
\hline BuP & $0.36 \pm 0.20$ & $0.60 \pm 0.25$ & $0.23 \pm 0.14$ & $0.06 \pm 0.068$ & $1.4 \pm 0.39$ & $1.1 \pm 0.23$ & $0.012 \pm 0.007$ & $0.004 \pm 0.003$ \\
\hline PrP & $0.079 \pm 0.042$ & $0.06 \pm 0.035$ & $0.034 \pm 0.018$ & $0.01 \pm 0.009$ & $0.17 \pm 0.07$ & $0.15 \pm 0.045$ & $0.004 \pm 0.003$ & $0.003 \pm 0.001$ \\
\hline ¿4Parabens & $1.3 \pm 0.64$ & $1.9 \pm 0.83$ & $1.1 \pm 0.55$ & $0.32 \pm 0.35$ & $4.2 \pm 0.85$ & $3.1 \pm 0.61$ & $0.066 \pm 0.027$ & $0.08 \pm 0.042$ \\
\hline CB28 & $0.23 \pm 0.11$ & $0.12 \pm 0.038$ & $0.12 \pm 0.063$ & $0.042 \pm 0.042$ & $0.57 \pm 0.13$ & $0.057 \pm 0.012$ & $0.022 \pm 0.011$ & $0.009 \pm 0.002$ \\
\hline CB52 & $1.0 \pm 0.52$ & $0.65 \pm 0.16$ & $0.35 \pm 0.15$ & $0.12 \pm 0.12$ & $1.7 \pm 0.33$ & $0.15 \pm 0.044$ & $0.067 \pm 0.039$ & $0.035 \pm 0.014$ \\
\hline CB101 & $0.22 \pm 0.044$ & $0.18 \pm 0.082$ & $0.10 \pm 0.099$ & $0.045 \pm 0.05$ & $0.91 \pm 0.87$ & $0.054 \pm 0.031$ & $0.041 \pm 0.02$ & $0.019 \pm 0.004$ \\
\hline CB118 & $0.025 \pm 0.015$ & $0.041 \pm 0.025$ & $0.016 \pm 0.012$ & $0.013 \pm 0.015$ & $0.006 \pm 0.009$ & $0.006 \pm 0.005$ & $0.013 \pm 0.007$ & $0.009 \pm 0.002$ \\
\hline CB138 & $0.076 \pm 0.084$ & $0.013 \pm 0.011$ & $0.053 \pm 0.07$ & $0.01 \pm 0.005$ & $0.007 \pm 0.002$ & $0.003 \pm 0.003$ & $0.015 \pm 0.005$ & $0.007 \pm 0.001$ \\
\hline CB153 & $0.099 \pm 0.097$ & $0.03 \pm 0.025$ & $0.067 \pm 0.079$ & $0.019 \pm 0.013$ & $0.01 \pm 0.005$ & $0.004 \pm 0.003$ & $0.02 \pm 0.005$ & $0.008 \pm 0.002$ \\
\hline CB180 & $0.17 \pm 0.26$ & $0.006 \pm 0.005$ & $0.10 \pm 0.17$ & $0.014 \pm 0.013$ & $0.01 \pm 0.011$ & $0.003 \pm 0.005$ & $0.02 \pm 0.008$ & $0.002 \pm 0.001$ \\
\hline CB77 & $<L O Q$ & $<L O Q$ & $0.001 \pm 0.001$ & $<L O Q$ & $<L O Q$ & $<L O Q$ & $<L O Q$ & $<L O Q$ \\
\hline CB81 & $0.003 \pm 0.001$ & $<L O Q$ & $0.002 \pm 0.002$ & $<L O Q$ & $<L O Q$ & $<\angle O Q$ & $0.002 \pm 0.001$ & $<L O Q$ \\
\hline CB126 & $<L O Q$ & $<L O Q$ & $<L O Q$ & $<L O Q$ & $<L O Q$ & $<L O Q$ & $<L O Q$ & $<L O Q$ \\
\hline CB169 & $<L O Q$ & $<L O Q$ & $0.001 \pm 0$ & $<L O Q$ & $<\angle O Q$ & $<L O Q$ & $<L O Q$ & $<\angle O Q$ \\
\hline CB105 & $0.008 \pm 0.005$ & $0.012 \pm 0.009$ & $0.004 \pm 0.004$ & $0.003 \pm 0.004$ & $0.002 \pm 0.003$ & $0.001 \pm 0.001$ & $0.006 \pm 0.003$ & $0.003 \pm 0.000$ \\
\hline CB114 & $<L O Q$ & $<L O Q$ & $<L O Q$ & $<L O Q$ & $<L O Q$ & $<\angle O Q$ & $<\angle O Q$ & $<L O Q$ \\
\hline CB123 & $<L O Q$ & $<L O Q$ & $<L O Q$ & $<L O Q$ & $<L O Q$ & $<L O Q$ & $0.017 \pm 0.007$ & $<L O Q$ \\
\hline CB156 & $0.008 \pm 0.011$ & $0.001 \pm 0.001$ & $0.007 \pm 0.01$ & $0.001 \pm 0.001$ & $0.001 \pm 0.001$ & $<L O Q$ & $0.001 \pm 0.001$ & $<L O Q$ \\
\hline CB157 & $0.001 \pm 0.001$ & $<L O Q$ & $<L O Q$ & $<L O Q$ & $<L O Q$ & $<L O Q$ & $<L O Q$ & $<L O Q$ \\
\hline CB167 & $0.002 \pm 0.004$ & $<L O Q$ & $0.002 \pm 0.003$ & $<L O Q$ & $<L O Q$ & $<\angle O Q$ & $<L O Q$ & $<L O Q$ \\
\hline CB189 & $0.002 \pm 0.003$ & $<L O Q$ & $0.001 \pm 0.001$ & $<L O Q$ & $<L O Q$ & $<L O Q$ & $<L O Q$ & $<L O Q$ \\
\hline CB110 & $0.088 \pm 0.023$ & $0.081 \pm 0.033$ & $0.042 \pm 0.043$ & $0.02 \pm 0.024$ & $0.32 \pm 0.22$ & $0.018 \pm 0.01$ & $0.022 \pm 0.01$ & $0.011 \pm 0.002$ \\
\hline$\Sigma 7 P C B i$ & $1.9 \pm 0.58$ & $1.05 \pm 0.34$ & $0.82 \pm 0.18$ & $0.27 \pm 0.24$ & $3.2 \pm 1.3$ & $0.28 \pm 0.07$ & $0.19 \pm 0.082$ & $0.089 \pm 0.021$ \\
\hline$\sum$ PCB-DL & $0.052 \pm 0.012$ & $0.054 \pm 0.036$ & $0.034 \pm 0.015$ & $0.017 \pm 0.02$ & $0.009 \pm 0.011$ & $0.006 \pm 0.006$ & $0.041 \pm 0.018$ & $0.012 \pm 0.002$ \\
\hline$\sum 19 \mathrm{PCBs}$ & $2.02 \pm 0.56$ & $1.1 \pm 0.39$ & $0.88 \pm 0.21$ & $0.29 \pm 0.26$ & $3.5 \pm 1.5$ & $0.3 \pm 0.079$ & $0.24 \pm 0.10$ & $0.10 \pm 0.023$ \\
\hline HCB & $0.11 \pm 0.048$ & $0.10 \pm 0.026$ & $0.17 \pm 0.09$ & $0.067 \pm 0.07$ & $0.006 \pm 0.003$ & $0.15 \pm 0.008$ & $0.049 \pm 0.037$ & $0.046 \pm 0.016$ \\
\hline PeCB & $0.14 \pm 0.065$ & $0.12 \pm 0.034$ & $0.16 \pm 0.067$ & $0.10 \pm 0.099$ & $0.002 \pm 0.002$ & $0.099 \pm 0.021$ & $0.013 \pm 0.014$ & $0.022 \pm 0.008$ \\
\hline BDE28 & $0.0012 \pm 0.0018$ & $0.0021 \pm 0.0004$ & $0.0004 \pm 0.0008$ & $<\angle O Q$ & $0.0031 \pm 0.0042$ & $<L O Q$ & $0.0001 \pm 0.0001$ & $0.0001 \pm 0.0000$ \\
\hline BDE47 & $0.041 \pm 0.0478$ & $0.043 \pm 0.0307$ & $0.0014 \pm 0.0024$ & $0.0009 \pm 0.0015$ & $0.026 \pm 0.032$ & $0.0057 \pm 0.0051$ & $0.0022 \pm 0.0014$ & $0.0035 \pm 0.0027$ \\
\hline BDE100 & $0.0039 \pm 0.0012$ & $0.0031 \pm 0.0015$ & $0.0008 \pm 0.0013$ & $<L O Q$ & $0.0007 \pm 0.0013$ & $<L O Q$ & $0.0008 \pm 0.0011$ & $0.0012 \pm 0.0012$ \\
\hline BDE99 & $0.016 \pm 0.0044$ & $0.012 \pm 0.0027$ & $0.0033 \pm 0.0057$ & $<L O Q$ & $0.005 \pm 0.0021$ & $0.0041 \pm 0.002$ & $0.003 \pm 0.003$ & $0.0024 \pm 0.0025$ \\
\hline BDE153 & $<L O Q$ & $<L O Q$ & $0.001 \pm 0.002$ & $<L O Q$ & $<L O Q$ & $<L O Q$ & $<L O Q$ & $<L O Q$ \\
\hline BDE154 & $0.0011 \pm 0.001$ & $0.0007 \pm 0.0006$ & $0.0011 \pm 0.0019$ & $<L O Q$ & $0 \pm 0$ & $<\angle O Q$ & $0.0002 \pm 0.0002$ & $<L O Q$ \\
\hline BDE183 & $<L O Q$ & $<L O Q$ & $<L O Q$ & $<L O Q$ & $<L O Q$ & $<L O Q$ & $<L O Q$ & $<L O Q$ \\
\hline BDE209 & $0.13 \pm 0.11$ & $0.005 \pm 0.01$ & $0.043 \pm 0.063$ & $0.04 \pm 0.052$ & $0.013 \pm 0.022$ & $0.031 \pm 0.053$ & $0.0076 \pm 0.0046$ & $<L O Q$ \\
\hline ¿8PBDEs & $0.19 \pm 0.172$ & $0.067 \pm 0.025$ & $0.051 \pm 0.077$ & $0.041 \pm 0.051$ & $0.048 \pm 0.062$ & $0.041 \pm 0.055$ & $0.014 \pm 0.011$ & $0.0072 \pm 0.0063$ \\
\hline ACY & $0.35 \pm 0.065$ & $0.012 \pm 0.012$ & $0.63 \pm 0.16$ & $0.002 \pm 0.003$ & $0.001 \pm 0.001$ & $0.01 \pm 0.006$ & $0.49 \pm 0.85$ & $0.34 \pm 0.59$ \\
\hline ACE & $0.96 \pm 1.6$ & $<\angle O Q$ & $<L O Q$ & $<L O Q$ & $3.6 \pm 1.1$ & $<L O Q$ & $1.0 \pm 0.76$ & $0.34 \pm 0.30$ \\
\hline FLU & $1.8 \pm 0.70$ & $4.6 \pm 0.84$ & $2.18 \pm 0.63$ & $1.6 \pm 1.7$ & $5.3 \pm 1.8$ & $0.008 \pm 0.015$ & $1.5 \pm 0.70$ & $1.0 \pm 0.87$ \\
\hline PHE & $2.9 \pm 1.2$ & $6.2 \pm 1.0$ & $3.1 \pm 1.1$ & $2.1 \pm 2.2$ & $5.0 \pm 1.9$ & $5.7 \pm 1.6$ & $3.8 \pm 1.2$ & $2.7 \pm 2.2$ \\
\hline ANT & $<L O Q$ & $0.007 \pm 0.004$ & $<L O Q$ & $<L O Q$ & $<L O Q$ & $0.007 \pm 0.003$ & $<L O Q$ & $0.068 \pm 0.057$ \\
\hline FTH & $0.21 \pm 0.019$ & $0.87 \pm 0.32$ & $0.12 \pm 0.098$ & $0.17 \pm 0.15$ & $0.21 \pm 0.091$ & $0.52 \pm 0.22$ & $0.61 \pm 0.15$ & $0.86 \pm 0.55$ \\
\hline Pyr & $0.15 \pm 0.046$ & $0.77 \pm 0.273$ & $0.093 \pm 0.066$ & $0.14 \pm 0.14$ & $0.16 \pm 0.084$ & $0.40 \pm 0.15$ & $0.47 \pm 0.15$ & $0.65 \pm 0.37$ \\
\hline $\mathrm{BaA}$ & $0.011 \pm 0.01$ & $0.12 \pm 0.084$ & $0.01 \pm 0.008$ & $1.3 \pm 2.3$ & $0.011 \pm 0.009$ & $0.07 \pm 0.042$ & $0.025 \pm 0.012$ & $0.15 \pm 0.084$ \\
\hline CHR & $0.017 \pm 0.014$ & $0.17 \pm 0.12$ & $0.015 \pm 0.013$ & $1.3 \pm 2.2$ & $0.013 \pm 0.01$ & $0.11 \pm 0.08$ & $0.051 \pm 0.023$ & $0.26 \pm 0.14$ \\
\hline $\mathrm{BbF}$ & $0.017 \pm 0.008$ & $0.23 \pm 0.13$ & $0.017 \pm 0.006$ & $0.016 \pm 0.027$ & $0.019 \pm 0.006$ & $0.115 \pm 0.052$ & $0.026 \pm 0.011$ & $0.21 \pm 0.10$ \\
\hline BkF & $<L O Q$ & $0.004 \pm 0.007$ & $<L O Q$ & $<L O Q$ & $<L O Q$ & $<L O Q$ & $<L O Q$ & $0.006 \pm 0.006$ \\
\hline BaP & $0.004 \pm 0.006$ & $0.141 \pm 0.06$ & $<L O Q$ & $0.03 \pm 0.019$ & $0.002 \pm 0.003$ & $0.10 \pm 0.041$ & $0.013 \pm 0.022$ & $0.12 \pm 0.084$ \\
\hline IcdP & $<L O Q$ & $<L O Q$ & $<L O Q$ & $<L O Q$ & $0.002 \pm 0.003$ & $<L O Q$ & $<L O Q$ & $<L O Q$ \\
\hline DahA & $<L O Q$ & $<L O Q$ & $<L O Q$ & $<L O Q$ & $<L O Q$ & $<\angle O Q$ & $<L O Q$ & $<L O Q$ \\
\hline Bghip & $0.013 \pm 0.006$ & $0.15 \pm 0.045$ & $0.013 \pm 0.012$ & $0.34 \pm 0.55$ & $0.01 \pm 0.009$ & $0.092 \pm 0.036$ & $0.023 \pm 0.012$ & $0.073 \pm 0.023$ \\
\hline
\end{tabular}


Table 2. Differences in indoor air concentrations (gas + particles) according to the type of building (Friedman test, $p<0.05, n=6$ ).

\begin{tabular}{|c|c|c|c|c|}
\hline & Compounds & $\begin{array}{c}\text { Significance } \\
p<0.05\end{array}$ & $\begin{array}{c}\text { Environment } \\
\text { significantly different }\end{array}$ & \\
\hline \multirow{3}{*}{ PAEs } & DEP & + & Nursery & \multirow{3}{*}{$\begin{array}{c}\text { Higher } \\
\text { concentrations }\end{array}$} \\
\hline & DEHP & + & Nursery & \\
\hline & ¿7PAEs & + & Nursery & \\
\hline BPA & & - & & \\
\hline APs & $\sum \mathrm{OP}+4-\mathrm{NP}$ & + & Nursery & $\begin{array}{c}\text { Higher } \\
\text { concentrations }\end{array}$ \\
\hline \multirow{2}{*}{ Parabens } & MeP & + & Nursery & \multirow{2}{*}{$\begin{array}{c}\text { Higher } \\
\text { concentrations }\end{array}$} \\
\hline & $\sum 4$ parabens & + & Nursery & \\
\hline \multirow{3}{*}{ PCBs } & CB-52 & + & Apartment & \multirow{3}{*}{$\begin{array}{c}\text { Lower } \\
\text { concentrations }\end{array}$} \\
\hline & $\sum 7 \mathrm{PCBi}$ & + & Apartment & \\
\hline & $\sum 19 \mathrm{PCBs}$ & + & Apartment & \\
\hline $\mathrm{HCB}$ & & - & & \\
\hline PECB & & - & & \\
\hline PBDEs & & - & & \\
\hline \multirow{3}{*}{$\mathrm{PAHs}$} & FLU & + & Nursery & \multirow{3}{*}{$\begin{array}{c}\text { Higher } \\
\text { concentrations }\end{array}$} \\
\hline & $\mathrm{BaP}$ & + & Nursery & \\
\hline & $\sum 8 \mathrm{PAHs}$ & - & & \\
\hline
\end{tabular}

Table 3. Relationships between SVOC concentrations in indoor air for all seasons and all buildings (Spearman coefficients; bold: significant $r$ values for $p<0.001, n=18$ ).

\begin{tabular}{|c|c|c|c|c|}
\hline & ¿7PAES & ¿4Parabens & $\Sigma O P+4-N P$ & $\Sigma 8 \mathrm{PAHs}$ \\
\hline$\sum$ 4Parabens & 0.822 & 1 & & \\
\hline$\Sigma O P+4-N P$ & 0.820 & 0.949 & 1 & \\
\hline$\Sigma 8 \mathrm{PAHS}$ & -0.401 & -0.144 & -0.271 & 1 \\
\hline$\Sigma 7 \mathrm{PCBi}$ & 0.643 & 0.727 & 0.799 & -0.265 \\
\hline
\end{tabular}



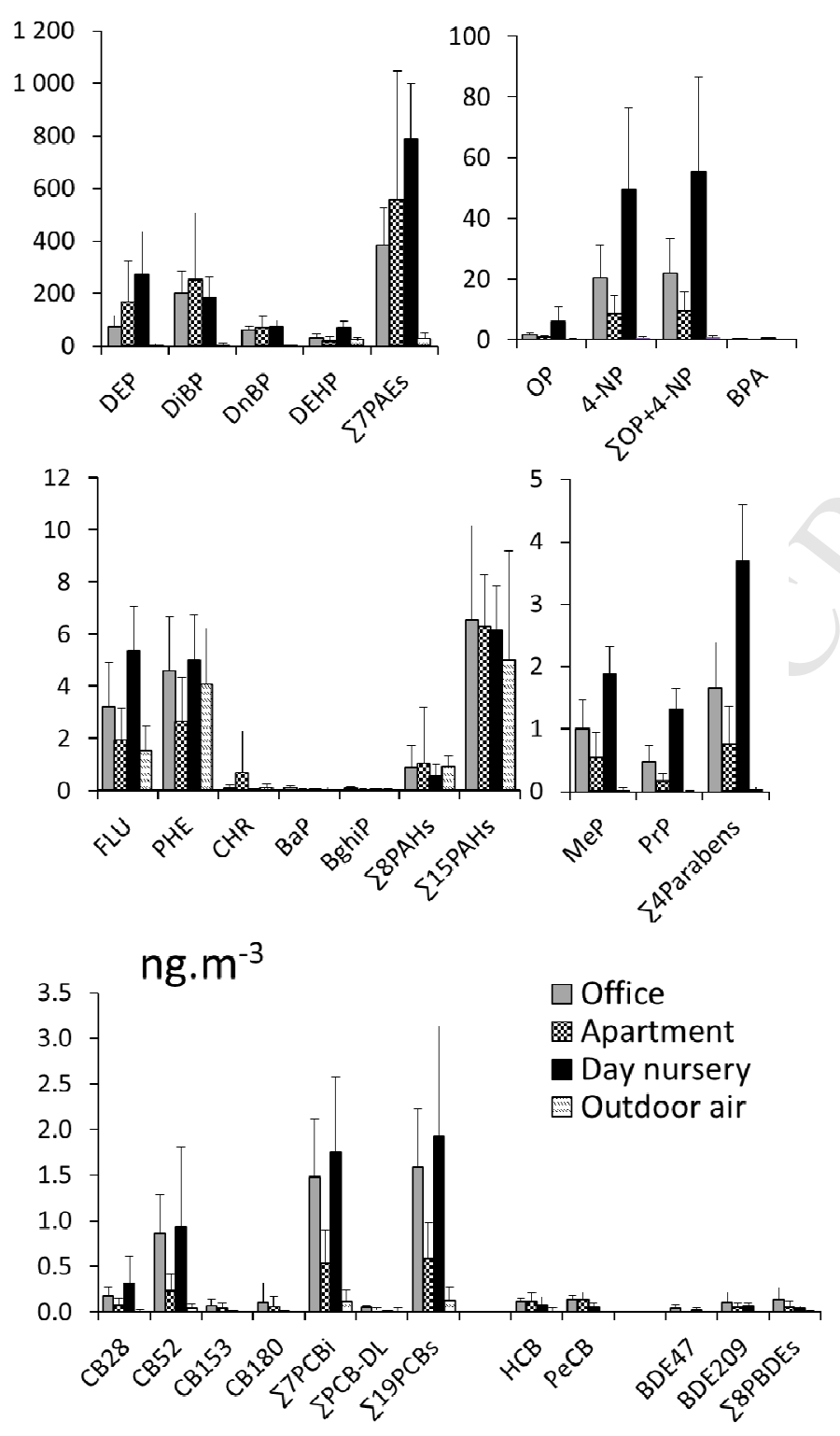

Figure 1: Individual SVOC concentrations (mean \pm SD, ng. ${ }^{-3}$ ) in indoor air (gas + particles) and in outdoor air in the centre of Paris. 

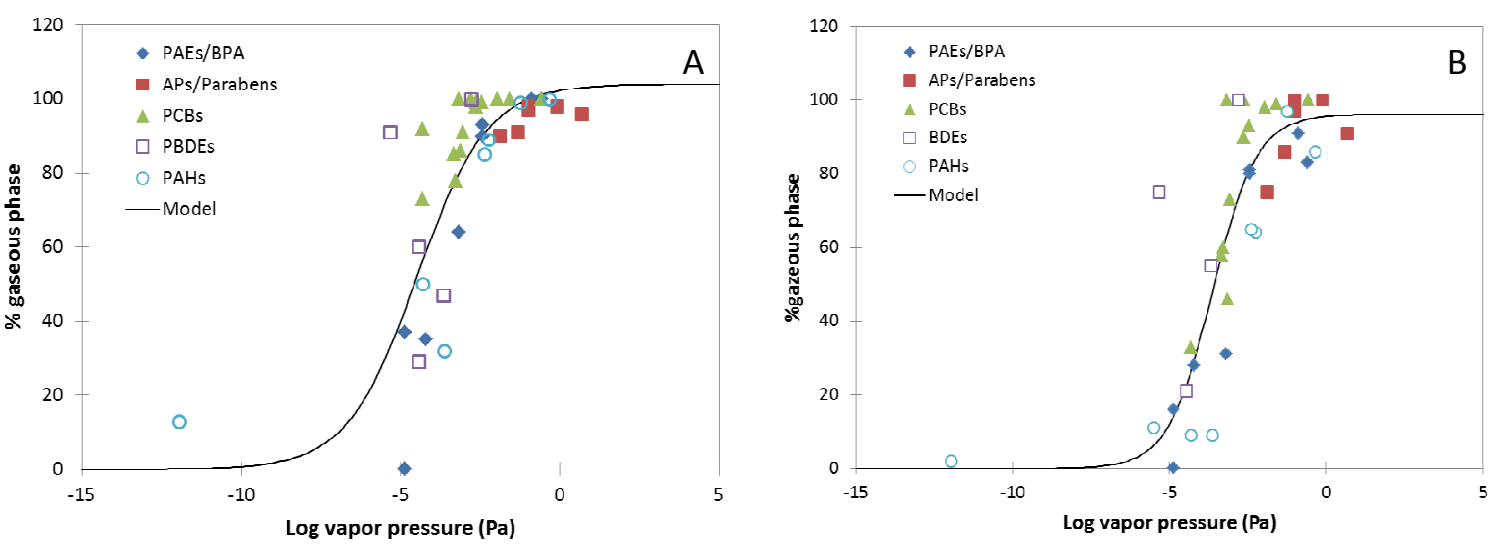

Figure 2: Vapor pressure vs. percentage in gaseous phase for the non-heating period (a) and heating period $(b)(n=41)$ 